\title{
Consciência morfossintática e ortografia em adolescentes e adultos escolarizados
}

\author{
Bianca Arruda Manchester Queiroga \\ Lúcia Maria Lins \\ Antônio Roazzi \\ Rafaella Asfora \\ Universidade Federal de Pernambuco
}

\begin{abstract}
Resumo
O objetivo do estudo foi avaliar o desempenho ortográfico e a consciência morfossintática em uma amostra composta por 224 adolescentes e adultos escolarizados. Foram aplicadas tarefas de ditado de palavras e pseudopalavras, julgamento e analogia de palavras, com justificativas, elaboradas com morfemas gramaticais e lexicais que apresentavam concorrência na representação gráfica dos fonemas $/ \mathrm{s} / \mathrm{e} / \mathrm{z} /$. Os resultados mostraram diferenças importantes entre os morfemas gramaticais e lexicais, sugerindo que tais princípios ortográficos não são apreendidos do mesmo modo. Também não se observou a utilização gerativa desses princípios, apesar de haver evolução na conduta ortográfica e nas explicitações entre o final do ensino fundamental e médio. Foi encontrado um efeito preditor do conhecimento explícito sobre o desempenho ortográfico na escrita de palavras e pseudopalavras. Conclui-se que mesmo nos níveis mais avançados de escolarização ainda há dificuldade na explicitação consciente desses princípios ortográficos.
\end{abstract}

Palavras-chave: consciência morfossintática; ortografia; adolescentes e adultos.

\begin{abstract}
Morphosyntactic awareness and spelling in schooled adolescents and adults. The aim of this study was to evaluate the spelling and morphosyntactic awareness in a sample of 224 schooled adolescents and adults. Participants were tested in a task of dictations of words and pseudowords, judgment of written words and analogy of words (both with justification) elaborated with grammatical and lexical morphemes that presents competition in the graphical representation of the fonemes / s / and / z /. The results showed significant differences between the morphemes grammatical and lexical, suggesting that these orthographic principles are not attained likewise. It was not also observed the use of generative principles, though it is possible to observe an evolution in the orthographic performance and in the type of justifications used at the end of primary and secondary education. A predictive effect of explicit knowledge about the orthographic performance in spelling words and pseudowords was also observed. It is concluded that even in the most advanced levels of schooling there is still difficulty in explicit aware of the orthographic principles.
\end{abstract}

Keywords: morphosyntactic awareness; spelling; adolescents and adults.

A s primeiras investigações sobre a apropriação da ortografia do português buscaram compreender, a partir dos erros ortográficos cometidos durante a fase de aprendizagem da notação ortográfica, como as crianças elaboram hipóteses acerca da ortografia e superam as dificuldades relativas a esta aprendizagem (Carraher, 1985). Concordando com a ideia de existir uma construção ativa por parte do aprendiz, Nunes, Bryant e Bindman (1995) argumentam que a ortografia não pode ser concebida como um processo reprodutivo porque as crianças geram a grafia das palavras, inclusive de palavras que jamais escreveram.
Mesmo em estudos conduzidos em línguas que requerem grandes sobrecargas de memorização, já se tem evidências empíricas que refletem este processo de construção ativa por parte do aprendiz. A escrita chinesa, por exemplo, é vista como uma exceção nos processos de aquisição da linguagem, uma vez que ela é aprendida por memorização. Entretanto, investigações psicolinguísticas descrevendo aspectos formais e informais da escrita chinesa, têm oferecido uma nova direção para uma análise cognitiva desta aquisição (Chan \& Nunes, 1998). De modo semelhante, Levin, Ravid e Rapaport (2001) observaram a relação do conhecimento morfológico com a aprendizagem da 
escrita em crianças falantes do hebraico.

Na língua portuguesa, os estudos ainda são incipientes, mas já se encontra evidências na mesma direção (Meirelles \& Correa 2005; Queiroga, Lins, \& Pereira, 2006; Rego \& Buarque, 1997). Queiroga et al. (2006), por exemplo, aplicaram uma tarefa de analogia de palavras com justificativa para 120 crianças do $3^{0}$ e $5^{\circ}$ Ano do ensino fundamental. A tarefa tinha o objetivo de avaliar o conhecimento dos participantes sobre os processos de formação de palavras no português. As justificativas apresentadas pelas crianças foram classificadas em sete categorias, sendo apenas uma delas indicativa do conhecimento morfossintático. Os resultados mostraram que o conhecimento morfossintático revelado pelo índice de acertos na tarefa de analogia não era suficiente para predizer o desempenho das crianças em ortografia. No entanto, quando as justificativas morfossintáticas foram consideradas, a tarefa tornou-se capaz de predizer o desempenho ortográfico.

Mota (2007) investigou o desenvolvimento da morfologia derivacional e o uso gerativo de princípios ortográficos em pseudopalavras, em crianças do $2^{\underline{O}}$ e $3^{\circ}$ ano do ensino fundamental. Os resultados mostraram que as crianças do segundo ano foram capazes de realizar julgamentos sobre a relação morfológica das palavras com níveis de acerto superiores a 50\%. A autora concluiu que esses julgamentos parecem demonstrar que as crianças são capazes de apresentar um grau de reflexão sobre a morfologia derivacional também no português. Além disso, foram encontradas correlações positivas entre a consciência morfológica e o desempenho ortográfico das crianças.

Mota, Aníbal e Lima (2008) investigaram a contribuição do processamento da morfologia derivacional sobre a leitura e escrita, e se esta contribuição seria independente da consciência fonológica. Os resultados assinalam que a habilidade de refletir sobre os morfemas contribui tanto para a leitura como para a escrita, e que essa contribuição é independente da consciência fonológica.

Deste modo, a tônica dos estudos mais recentes tem sido compreender como ocorre a relação entre a consciência morfossintática e a leitura e escrita e, de modo específico, com a apropriação ortográfica, ao longo da interação da criança com a língua escrita, considerando as peculiaridades das normas e princípios ortográficos e as habilidades linguísticas, metalinguísticas e cognitivas dos próprios aprendizes (Meirelles \& Correa, 2005; Mota, 2007; Mota et al., 2008; Queiroga et al., 2006, Rego \& Buarque, 1997).

Alguns estudos (Cavalcante, 2000; Guimarães, 1994; Morais 1995, 1996; Nunes et al., 1995; Queiroga et al., 2006; Vasconcelos, 1999) ressaltam, ainda, a ideia de que é necessário buscar meios para se acessar o conhecimento explícito dos sujeitos em fase de aprendizagem da notação ortográfica e de desenvolver estratégias que facilitem uma reflexão metalinguística a este respeito. Porém, também há evidências de que muitos dos aspectos investigados não chegam a ser completamente compreendidos, mesmo quando o conhecimento morfossintático foi investigado em populações que abrangiam os últimos anos do ensino médio (Guimarães, 1994; Vasconcelos, 1999).

Contudo, não foi proposto em nenhum destes estudos a observação da influência dos níveis finais da escolarização sobre a compreensão de aspectos morfossintáticos da ortografia, buscando elementos que pudessem desvendar as dificuldades que, por ventura, permaneçam mesmo depois de todo o processo de escolarização, o que poderia ser um importante norteador do ensino da ortografia. Além disso, estes estudos não compararam a aquisição de várias regras ou princípios ortográficos de natureza morfossintática em uma mesma população.

Com estas considerações em pauta, o presente estudo se propôs a investigar se adolescentes e adultos com diferentes níveis de escolarização são capazes de usar gerativamente princípios ortográficos de natureza morfossintática e se são capazes de explicitar a consciência desses princípios. De modo específico o estudo objetivou, ainda, verificar em que medida os níveis de ensino (fundamental, médio e superior) contribuem para a aquisição ortográfica e se haveria influência da área de estudo escolhida em uma formação superior sobre esta aquisição.

Um exemplo de regularidade oriunda da morfossintaxe é a influência de alguns morfemas na determinação da grafia das palavras quando existe uma situação de concorrência na representação gráfica dos fonemas /s/ e /z/, como aponta Faraco (1992). Esta foi, então, a fonte de regularidade escolhida para ser investigada no presente estudo.

\section{Método}

\section{Amostra}

Participaram do estudo 224 adolescentes e adultos, distribuídos em quatro grupos, sendo 56 deles concluintes do $2^{\underline{o}}$ ciclo do ensino fundamental (EF), 56 concluintes do ensino médio (EM) e 112 universitários em fase de conclusão de curso (último ano), sendo 56 alunos de cursos da área das Ciências Humanas e 56 alunos de cursos da área das Ciências Exatas.

Todos os participantes do ensino fundamental e médio eram alunos de escolas particulares, do Município de Olinda$\mathrm{PE}$, frequentada por crianças de nível socioeconômico médio. Os participantes universitários eram alunos de duas grandes Universidades do Estado de Pernambuco, ambas situadas na Cidade do Recife- PE. Todos os cuidados éticos preconizados na Resolução 196/96 do Conselho Nacional de Ética em Pesquisa foram seguidos.

\section{Material}

As palavras utilizadas na composição das tarefas foram escolhidas a partir da consideração de duas fontes de regularidades ortográficas de caráter morfossintático: Morfemas Gramaticais (Sufixos: -eza, -esa, -ez, -ês, -ense, -ice, -sse(m), -oso(a), -aço(a), -izar e Desinência Verbal -isse) e Morfemas Lexicais (Radicais: cabeç-, braç-, impress-, excet-, avis-, poss, coz- organiz-, prez- e desliz-). Todos os morfemas foram escolhidos por apresentarem uma situação de concorrência na representação gráfica dos fonemas /s/ e /z/, o que leva a uma elevada possibilidade de acontecer erros de grafia. Por esta razão, o conhecimento destes sufixos (incluindo uma desinência verbal) e radicais constituía um elemento indispensável para a escolha da grafia correta das palavras e pseudopalavras que compuseram as tarefas. 
Kehdi (2001) oferece uma boa descrição dos morfemas do português, a partir de uma postura sincrônica, afirmando acreditar que o conhecimento dos mecanismos de funcionamento de um idioma no seu estado atual deve anteceder as explicações de caráter histórico. $\mathrm{O}$ autor parte do princípio de que uma palavra é um elemento de constituição complexa, cuja análise poderá conduzir a uma base rigorosa para os estudos morfológicos. Sobre a classificação dos morfemas, Kehdi (2001) afirma que os morfemas de valor lexical pertencem a um inventário aberto (seu número é indeterminado e é sempre possível acrescentar um novo membro à série). Já os morfemas de valor gramatical constituem inventários fechados, representados por elementos de número reduzido, cuja listagem figura nas gramáticas (ex: os afixos, as preposições).

\section{Procedimento}

Todos os participantes realizaram quatro tarefas: Ditado de palavras; ditado de não-palavras ou peudopalavras; julgamento de grafias (com justificativa) e analogia de palavras (com justificativa).

Para se evitar um possível efeito de treinamento ou memorização, a ordem de apresentação das tarefas foi randomizada, através de um quadrado latino, de modo que cada grupo de participantes passasse por quatro ordens de apresentação distintas. Esta medida de controle foi muito importante para se evitar possíveis efeitos de ordem ou memorização na análise dos desempenhos dos participantes nas quatro tarefas do estudo, considerando-se que os estímulos (morfemas) foram os mesmos em todas as tarefas.

Assim, de forma preliminar foi realizada uma análise de variância (one-way ANOVA) tomando a variável ordem de apresentação como fator e as médias dos acertos totais nas quatro tarefas como variáveis dependentes. Os resultados revelaram que não houve influência da ordem de apresentação sobre o desempenho dos participantes.

$\mathrm{Na}$ tarefa de ditado de palavras e pseudopalavras foi considerado como critério para determinar acerto ou erro a escrita ortográfica do morfema investigado (ou seja, a representação gráfica dos fonemas /s/ ou /z/ no morfema estudado). Outros erros ocorridos em outras posições na palavra não foram computados. Esta tarefa foi realizada conforme o modelo de Rego e Buarque (1997), no qual as palavras ditadas são apresentadas em um contexto de frases a serem completadas. $\mathrm{O}$ examinador procurou realizar o ditado em pronúncia neutra, ou seja, na pronúncia comum à região onde o estudo foi conduzido. $\mathrm{O}$ objetivo do ditado de palavras foi obter uma medida da conduta ortográfica dos participantes (ex: A menina nasceu na Tailândia, ela era / tailandesa). Já o ditado de pseudopalavras teve um objetivo distinto: avaliar o uso gerativo das regras ou princípios ortográficos estudados (ex: A avó da criança nasceu na Burlania, ela era /burlanesa).

$\mathrm{Na}$ tarefa de julgamento de grafias (JG) foi realizada uma adaptação do procedimento utilizado por Vasconcelos (1999), que consistia em solicitar ao participante o julgamento sobre a convencionalidade das palavras que eram apresentadas isoladamente. No presente estudo, havia o interesse em investigar o conhecimento de grafias através da utilização das pistas morfossintáticas e, dessa forma, as palavras precisavam ser apresentadas em contextos de frases.

Para cada sufixo, desinência ou radical foram apresentadas duas frases, sendo que em uma a palavra era apresentada com a grafia correta e em outra a palavra era grafada com violações ortográficas. Vale ressaltar, que as grafias incorretas constituíam violações possíveis de serem cometidas nos respectivos contextos, no que se refere à representação gráfica dos fonemas /s/ e /z/. Esta tarefa teve o objetivo de avaliar o conhecimento explícito dos participantes, quanto às representações ortográficas estudadas (ex: Minha avó era fluminense; tenho dois filhos piauiensses).

As justificativas observadas foram separadas em categorias e comparadas com os níveis de explicitação observados em outros estudos, a exemplo de Morais (1995, 1996), que analisou os níveis de explicitação obtidos em uma tarefa de transgressão intencional segundo o modelo de Karmiloff-Smith (citado por Morais 1995, 1996), e Vasconcelos (1999), que analisou as justificativas oferecidas pelos participantes em uma tarefa de julgamento.

A tarefa de analogia de palavras (AP) foi um procedimento inovador do presente estudo e teve a proposta de avaliar o nível de consciência dos participantes sobre os processos de formação de palavras em português, neste caso, tratando especificamente, dos processos derivacionais por sufixação (ex: GRANDEZA / MOLEZA) e pela manutenção dos radicais semânticos (ex: IMPRESSIONADO/ IMPRESSIONANTE).

A tarefa consistiu na comparação de similaridades (analogia) entre pares de grafias corretas. Isto é, os participantes relatavam, verbalmente, quais semelhanças percebiam entre os pares de palavras apresentadas e, em seguida, deviam apresentar uma explicação (justificativa) para essa semelhança. Esses relatos foram gravados para viabilizar a transcrição e categorização das respostas.

\section{Resultados}

Inicialmente, será apresentada uma comparação entre os grupos na utilização das regras ortográficas relativas aos morfemas gramaticais (sufixos e desinência) e no conhecimento explícito destas regularidades. É importante ressaltar que a medida do "conhecimento explícito" foi obtida pela consideração das justificativas nas tarefas de julgamento de grafias e analogia de palavras.

A tarefa de julgamento de grafias, de modo especial, pode ser influenciada tanto pela possibilidade de acertos ao acaso, já que possui apenas duas opções de resposta, quanto pela utilização de estratégias baseadas na memorização ou conhecimento prévio das palavras. Já a tarefa de analogia de palavras requer, mesmo antes da justificativa, algum nível de conhecimento sobre os processos envolvidos na formação das palavras, mas, mesmo assim, parece ser influenciada pelo grau de familiaridade diante do morfema e do contexto apresentado.

Um aspecto que dificultou a interpretação das justificativas foi que os participantes, com certa frequência, utilizavam apenas a "confirmação ou a correção da grafia" (ex: "porque eu sei que é assim", "já vi assim antes”) ou a "não justificativa” (ex: "não 
sei”) para justificarem suas respostas. Essas justificativas, no entanto, não são suficientes para assegurar que os participantes utilizaram as pistas morfossintáticas na determinação das respostas. Dentre as categorias de resposta observadas, apenas as justificativas em que foram verbalizados os "aspectos morfossintáticos" poderiam assegurar a compreensão dos princípios morfossintáticos envolvidos em cada caso.

Por esta razão, para que fosse possível comparar a consciência morfossintática (em um nível explícito) entre os grupos investigados, optou-se por considerar como acerto, em ambas as tarefas (JG e AP), apenas quando os participantes ofereciam justificativas baseadas em "aspectos morfossintáticos".

Os índices de acertos nos ditados de palavras e pseudopalavras obtidos para os morfemas gramaticais também foram computados nesta análise, a fim de obtermos um perfil da evolução na utilização das regras ortográficas determinadas pelos morfemas gramaticais. A Tabela 1 indica as médias de acertos para os morfemas gramaticais na escrita de palavras e pseudopalavras e nas tarefas de JG e AP.

É importante observar as grandes diferenças de desempenho

Tabela 1

Média e desvio padrão (entre parênteses) do total de acertos em cada tarefa, em cada grupo investigado para os morfemas gramaticais

\begin{tabular}{lcccc}
\hline \multicolumn{1}{c}{ Grupo } & Ditado Palavras & $\begin{array}{c}\text { Ditado } \\
\text { Pseudopalavras }\end{array}$ & $\begin{array}{c}\text { Julgamento } \\
\text { Grafias }\end{array}$ & $\begin{array}{c}\text { Analogia } \\
\text { Palavras }\end{array}$ \\
\hline \multirow{2}{*}{ Concluintes Fundamental } & 14,0 & 11,89 & 0,77 & 1,36 \\
& $(2,52)$ & $(3,35)$ & $(1,93)$ & $(1,54)$ \\
Concluintes Ensino Médio & 16,21 & 12,98 & 2,32 & 2,64 \\
& $(2,69)$ & $(3,07)$ & $(3,09)$ & $(2,01)$ \\
Superior Humanas & 16,88 & 13,73 & 1,61 & 2,16 \\
\multirow{2}{*}{ Superior Exatas } & $(2,55)$ & $(2,96)$ & $(2,53)$ & $(2,16)$ \\
& 16,61 & 13,27 & 1,80 & 2,30 \\
& $(2,85)$ & $(3,37)$ & $(2,46)$ & $(2,42)$ \\
\hline
\end{tabular}

Escores máximos - Ditado de Palavras, Ditado de Pseudopalavras e Julgamento de Grafias = 20; Analogia de palavras $=10$

entre as tarefas que avaliaram a consciência morfossintática e as tarefas que avaliaram a utilização das regras, considerando-se os escores totais para cada tarefa.

Estas médias foram submetidas a Análises de Variância oneway envolvendo a escolaridade como fator (4 grupos: $9^{-}$ano EF, $3^{0}$ ano EM, universitários humanas e universitários exatas) e as médias de acerto em cada tarefa como variáveis dependentes. Estas análises revelaram um aumento na média de acertos em função do avanço nos níveis de escolarização: ditado de palavras $[F(3,223)=96,27 ; p<0,01]$, ditado de pseudopalavras $[F(3,223)$ $=3,35 ; p<0,05]$, julgamento de grafias $[F(3,223)=3,64 ; p<$ $0,01]$, e analogia de palavras $[F(3,223)=3,92 ; p<0,01]$.

Com a finalidade de investigar em quais níveis de ensino as diferenças de desempenho nas tarefas investigadas foram significativas, foi realizado um pós-teste, que comparou, dois a dois, os quatro grupos de escolaridade. O pós-teste Tukey revelou que foram significativas as diferenças entre os seguintes desempenhos: a) Na tarefa de DP foi significativa a diferença de desempenho do $9^{\mathrm{O}}$ ano EF (média 14,0), em relação ao $3^{\mathrm{O}}$ ano EM, universitários humanas e universitários exatas (médias $16,21,16,88$ e 16,61 , respectivamente; $p<0,01$ ); b) Na tarefa de DPP foi significativa a diferença entre o desempenho da $9^{0}$ Ano (média 11,89) em relação ao desempenho do $3^{0}$ ano, universitários humanas e universitários exatas (médias 12,98, 13,73 e 13,27, respectivamente; $p<0,01$ ); c) Na tarefa de JG foi significativa a diferença entre o desempenho do $9^{-}$ano EF (média 0,77 ) e o $3^{\underline{0}}$ ano EM (média 2,32; $p<0,01$ ) e o desempenho do $9^{\underline{0}}$ ano EF em relação aos universitários humanas e exatas (médias 1,61, 1,80; $p<0,05$ ); d) Na tarefa de AP foi significativa a diferença entre o desempenho do $9^{\underline{0}}$ ano EF (média 1,36) em relação ao desempenho do $3^{\circ}$ ano EM, universitários humanas e universitários exatas (média 2,64, 2,16 e 2,30, respectivamente; $p<0,01)$

Estes resultados indicam, portanto, a influência da escolaridade sobre o desempenho dos participantes, tanto na utilização das regras baseadas nos morfemas gramaticais, quanto no conhecimento explícito destas regras e apontam a evolução na apropriação destas regras no período compreendido entre o final do ensino fundamental e o ensino médio.

Como o objetivo de investigar a predição das tarefas que avaliaram o conhecimento explícito, envolvido na compreensão dos aspectos morfossintáticos, sobre a escrita de palavras e pseudopalavras que possuem situações de concorrência na representação do /s/ e /z/ e que podem ser resolvidas através da consideração de pistas morfossintáticas, foram realizadas Análises de Regressões Múltiplas com passos fixos.

As regressões múltiplas proporcionam informações sobre a natureza da relação entre as variáveis dependente (VD) e independente (VI), indicando qual VI é preditora da VD, bem como o nível desta predição, explicado através da variância da $\mathrm{VD}$, controlando-se o efeito de variáveis intervenientes.

No presente estudo, controlamos o efeito da idade dos participantes e submetemos os escores obtidos por cada participante, em cada tarefa, às Análises de Regressão. Os resultados destas análises estão apresentados na tabela a seguir.

Com relação à variável de controle foi observado um efeito significativo da idade tanto para a escrita de palavras $[F(1,222)$ $=22,54 ; p<0,01]$, quanto para a escrita de pseudopalavras $[F(1,222)=4,76 ; p<0,05]$, explicando uma variância de $9 \%$ e $2 \%$, respectivamente.

Após a eliminação da influência desta variável foram inseridas as variáveis que investigaram. a consciência morfossintática Foi encontrado um efeito preditivo das tarefas de julgamento de grafias e analogia de palavras sobre a escrita 
Tabela 2

Análises de regressões múltiplas com passos fixos, tendo como variável dependente o desempenho na escrita de palavras e pseudopalavras e, como variáveis independentes: $1^{\circ}$ passo-idade e como $2^{\circ}$ e $3^{\circ}$ passos - os desempenhos na tarefa de Julgamento de Grafias e Analogia de Palavras (alternados), considerando os escores rígidos de acertos para os morfemas gramaticais, em todos os grupos de escolaridade

\begin{tabular}{|c|c|c|c|c|c|c|c|c|}
\hline \multirow{3}{*}{ Passos/Variáveis Preditivas } & \multicolumn{8}{|c|}{ Desempenho na Escrita } \\
\hline & \multicolumn{4}{|c|}{ Palavra } & \multicolumn{4}{|c|}{ Pseudopalavra } \\
\hline & $R^{2 \mathrm{ch}}$ & $F^{\mathrm{ch}}$ & $g l$ & $p$ & $R^{2 \mathrm{ch}}$ & $F^{\mathrm{ch}}$ & $g l$ & $p$ \\
\hline 1. Idade & 0,09 & 22,54 & $1-222$ & 0,001 & 0,02 & 4,76 & $1-222$ & 0,030 \\
\hline 2. Total de acertos Julgamento & 0,12 & 33,38 & $1-221$ & 0,001 & 0,10 & 26,41 & $1-221$ & 0,001 \\
\hline 3. Total de acertos Analogia & 0,05 & 15,27 & $1-220$ & 0,001 & 0,07 & 20,54 & $1-220$ & 0,001 \\
\hline 2. Total de acertos Analogia & 0,13 & 36,92 & $1-221$ & 0,001 & 0,15 & 41,15 & $1-221$ & 0,001 \\
\hline 3. Total de acertos Julgamento & 0,04 & 12,04 & $1-220$ & 0,001 & 0,03 & 7,02 & $1-220$ & 0,009 \\
\hline
\end{tabular}

de palavras e pseudopalavras, quando introduzidas como $2^{\underline{0}} \mathrm{e}$ como $3^{\underline{0}}$ passos.

Quando introduzida como $2^{\underline{0}}$ passo, a tarefa de JG apresentou um efeito preditivo sobre a escrita de palavras $[F(1,221)=33,38 ; p<0,01]$, explicando $12 \%$ da variância, e sobre a escrita de pseudopalavras $[F(1,221)=26,41 ; p<0,01]$, explicando $10 \%$ da variância. Quando foi introduzida como $3^{\underline{0}}$ passo, também apresentou um efeito preditivo sobre a escrita de palavras $[F(1,220)=12,04 ; p<0,01]$, explicando $4 \%$ da variância, e sobre a escrita de pseudopalavras $[F(1,220)=7,02$; $p<0,01$ ], explicando $3 \%$ da variância.

De modo semelhante, a tarefa de AP, quando introduzida como $2^{\underline{o}}$ passo, apresentou um efeito preditivo sobre a escrita de palavras $[F(1,221)=36,92 ; p<0,01]$, explicando $13 \%$ da variância, e sobre a escrita de pseudopalavras $[F(1,221)=41,15$; $p<0,01$ ], explicando $15 \%$ da variância. Quando foi introduzida como $3^{-}$passo, a tarefa manteve o efeito preditivo sobre a escrita de palavras $[F(1,220)=15,27 ; p<0,01]$, explicando $5 \%$ da variância, e sobre a escrita de pseudopalavras $[F(1,220)=20,54$; $p<0,01]$, explicando $7 \%$ da variância.

A maior explicação da variância na tarefa de AP sobre a escrita de pseudopalavras é um aspecto que denota que, de fato, a escrita gerativa depende desta capacidade de reflexão sobre a regra, uma vez que nesta condição as pistas oriundas do conhecimento prévio são neutralizadas. Estes resultados confirmam a influência da consciência morfossintática sobre o desempenho na escrita regular e gerativa dos participantes, em contextos ortográficos que demandam a utilização de regularidades oriundas da morfossintaxe.

A mesma análise foi realizada para investigar o desempenho dos participantes nas tarefas diante dos morfemas lexicais. A Tabela 3 indica as médias de acertos para os morfemas lexicais na escrita de palavras e pseudopalavras e nas tarefas de JG e AP, de acordo com o critério que considera as justificativas explícitas.

Tabela 3

Média e desvio padrão (entre parênteses) do total de acertos em cada tarefa, em cada grupo investigado para os morfemas lexicais

\begin{tabular}{lcccc}
\hline \multicolumn{1}{c}{ Grupo } & DitadoPalavras & $\begin{array}{c}\text { Ditado } \\
\text { Pseudopalavras }\end{array}$ & $\begin{array}{c}\text { Julgamento } \\
\text { Grafias }\end{array}$ & $\begin{array}{c}\text { Analogia } \\
\text { Palavras }\end{array}$ \\
\hline \multirow{2}{*}{ Concluintes Fundamental } & 16,04 & 14,61 & 3,86 & 1,75 \\
& $(2,62)$ & $(3,45)$ & $(4,57)$ & $(3,25)$ \\
Concluintes Ensino médio & 17,70 & 16,31 & 5,48 & 5,79 \\
\multirow{2}{*}{ Superior Humanas } & $(2,41)$ & $(3,09)$ & $(4,77)$ & $(3,63)$ \\
\multirow{2}{*}{ Superior Exatas } & 18,41 & 17,07 & 4,27 & 6,57 \\
& $(1,71)$ & $(2,09)$ & $(4,57)$ & $(3,16)$ \\
& 18,32 & 17,07 & 5,16 & 5,18 \\
& $(1,76)$ & $(3,12)$ & $(4,76)$ & $(3,37)$ \\
\hline
\end{tabular}

Escores máximos - Ditado de Palavras, Ditado de Pseudopalavras e Julgamento de Grafias = 20; Analogia de Palavras $=10$

Aqui também, é importante observar as grandes diferenças de desempenho entre as tarefas que avaliaram a consciência morfossintática e as tarefas que avaliaram a utilização das regras, considerando-se os escores totais para cada tarefa.

Estas médias foram submetidas a Análises de Variância oneway envolvendo a escolaridade como fator (4 grupos: do $9^{-}$ano EF, $3^{\circ}$ ano EM, universitários humanas e universitários exatas) e as médias de acerto em cada tarefa como variáveis dependentes.

Esta análise revelou um efeito significativo da escolaridade sobre os desempenhos na escrita de palavras $[F(3,223)=14,49 ; p$ $<0,01]$ e pseudopalavras $[F(3,223)=8,42, p<0,01]$, e também na tarefa de consciência morfossintática $[F(3,223)=22,43 ; p$ $<0,01]$.
O pós-teste Tukey, revelou que foram significativas as seguintes diferenças: a) No DP, entre os desempenhos do $3^{\underline{0}}$ ano EM (média 17,70), universitários humanas (média 18,41) e universitários exatas (média 18,32), em relação ao desempenho do $9^{\underline{0}}$ ano EF (média 16,04; $p<0,01$ ); b) No DPP, entre os desempenhos do $3^{\circ}$ ano EM (média 16,31), universitários humanas (média 17,07) e universitários exatas (média 17,07), em relação ao desempenho do $9^{\circ}$ ano EF (média 14,61; $p<$ $0,01)$; c) Na AP entre os desempenhos do $3^{\circ}$ ano EM (média 5,79), universitários humanas (média 6,57) e universitários exatas (média 5,18), em relação ao desempenho do $9^{0}$ ano $\mathrm{EF}$ (média 1,75; $p<0,01$ ).

Estes resultados ratificam, portanto, a evolução na utilização 
e compreensão dos princípios geradores relativos aos morfemas lexicais, também observada nos morfemas gramaticais, no período compreendido entre o final do ensino fundamental e médio.

Como o objetivo de investigar a predição das tarefas que avaliaram a consciência metalinguística envolvida na compreensão dos aspectos morfossintáticos sobre a escrita de palavras e pseudopalavras que possuem situações de concorrência na representação do /s/ e /z/ e que podem ser resolvidas através da consideração das pistas morfossintáticas, foram realizadas análises de regressões múltiplas com passos fixos.
De modo idêntico ao que foi realizado na análise dos morfemas gramaticais, foi adotado um critério rígido de acertos para estabelecer a predição entre a habilidade metalingüística investigada e o desempenho ortográfico dos participantes. Assim, foi considerado acerto apenas quando os participantes ofereciam justificativas explícitas verbais nas tarefas de julgamento e analogia de palavras. Os escores obtidos por cada sujeito, em cada tarefa, foram submetidos às Análises de Regressão com passos fixos, controlando-se o efeito da idade dos participantes. A tabela, a seguir, mostra o resultado desta análise.

Com relação à variável de controle foi observado um efeito

Tabela 4

Análises de regressões múltiplas com passos fixos, tendo como variável dependente o desempenho na escrita de palavras e pseudopalavras e, como variáveis independentes: $1^{\circ}$ passo-idade e como $2^{\circ}$ e $3^{\circ}$ passos - os desempenhos na tarefa de Julgamento de Grafias e Analogia de Palavras (alternados), considerando os escores rígidos de acertos para os morfemas lexicais, em todos os grupos de escolaridade

\begin{tabular}{|c|c|c|c|c|c|c|c|c|}
\hline \multirow{3}{*}{ Passos/Variáveis Preditivas } & \multicolumn{8}{|c|}{ Desempenho na Escrita } \\
\hline & \multicolumn{4}{|c|}{ Palavra } & \multicolumn{4}{|c|}{ Pseudopalavra } \\
\hline & $R^{2 \mathrm{ch}}$ & $F^{\mathrm{ch}}$ & $g l$ & $p$ & $R^{2 \mathrm{ch}}$ & $F^{\mathrm{ch}}$ & $g l$ & $p$ \\
\hline 1. Idade & 0,13 & 31,77 & $1-222$ & 0,001 & 0,07 & 17,74 & $1-222$ & 0,001 \\
\hline 2. Total de acertos Julgamento & 0,07 & 19,63 & $1-221$ & 0,001 & 0,05 & 13,03 & $1-221$ & 0,001 \\
\hline 3. Total de acertos Analogia & 0,06 & 19,16 & $1-220$ & 0,001 & 0,07 & 19,03 & $1-220$ & 0,001 \\
\hline 2. Total de acertos Analogia & 0,10 & 27,09 & $1-221$ & 0,001 & 0,10 & 25,52 & $1-221$ & 0,001 \\
\hline 3. Total de acertos Julgamento & 0,04 & 11,97 & $1-220$ & 0,001 & 0,03 & 6,93 & $1-220$ & 0,001 \\
\hline
\end{tabular}

significativo da idade tanto para a escrita de palavras $[F(1,222)$ $=31,77 ; p<0,01]$, quanto para a escrita de pseudopalavras $[F(1,222)=17,74 ; p<0,01]$, explicando uma variância de $13 \%$ e $7 \%$, respectivamente.

Após a eliminação da influência desta variável foram inseridas as variáveis que investigaram a consciência morfossintática. Foi encontrado um efeito preditivo das tarefas de julgamento de grafias e analogia de palavras sobre a escrita de palavras e pseudopalavras, quando introduzidas como $2^{-} \mathrm{e}$ como $3^{\underline{0}}$ passos.

Quando introduzida como $2^{\circ}$ passo, a tarefa de JG apresentou um efeito preditivo sobre a escrita de palavras $[F(1,221)=19,63 ; p<0,01]$, explicando $7 \%$ da variância, e sobre a escrita de pseudopalavras $[F(1,221)=13,03 ; p<0,01]$, explicando $5 \%$ da variância. Quando foi introduzida como $3^{\circ}$ passo, também apresentou um efeito preditivo sobre a escrita de palavras $[F(1,220)=11,97 ; p<0,01]$, explicando $4 \%$ da variância, e sobre a escrita de pseudopalavras $[F(1,220)=6,93$; $p<0,01$ ], explicando $3 \%$ da variância.

De modo semelhante, a tarefa de AP, quando introduzida como $2^{\underline{o}}$ passo, apresentou um efeito preditivo sobre a escrita de palavras $[F(1,221)=27,09 ; p<0,01]$, explicando $10 \%$ da variância, e sobre a escrita de pseudopalavras $[F(1,221)=25,52$; $p<0,01$ ], explicando $10 \%$ da variância. Quando foi introduzida como $3^{\underline{0}}$ passo, a tarefa manteve o efeito preditivo sobre a escrita de palavras $[F(1,220)=19,16 ; p<0,01]$, explicando $6 \%$ da variância, e sobre a escrita de pseudopalavras $[F(1,220)=19,03$; $p<0,01$ ], explicando $7 \%$ da variância.

Estes resultados também confirmaram a influência da consciência morfossintática sobre o desempenho na escrita regular e gerativa dos participantes, em contextos ortográficos que demandam a utilização de regularidades oriundas da morfossintaxe.

\section{Discussão e considerações finais}

Os resultados do presente estudo contribuem para o entendimento da apropriação ortográfica em uma faixa etária pouco estudada pelas investigações já conduzidas até o momento, corroborando os resultados de estudos que propõem a inexistência de uma sequência de apropriação linear na utilização das regularidades de contexto morfossintático e com os que indicam uma estreita conexão entre a habilidade de refletir, de maneira explícita e verbal, sobre os aspectos morfossintáticos e a apropriação de princípios ortográficos de natureza morfossintática (Morais 1995, 1996; Nunes et al., 1995).

A existência da relação entre a consciência morfossintática e a apropriação ortográfica, corroborada na presente investigação, oferece subsídios para importantes questões educacionais, principalmente para a necessidade de se desenvolver estratégias que facilitem uma reflexão metalinguística sobre os aspectos morfossintáticos da ortografia, concordando com estudos já realizados (Cavalcante, 2000; Guimarães, 1994; Morais, 1995, 1996; Queiroga et al., 2006; Rego \& Buarque, 1997; Vasconcelos, 1999).

Assim, os resultados do presente estudo apontam para a necessidade de desenvolvimento de uma prática pedagógica mais reflexiva, uma vez que a utilização de estratégias baseadas na memorização ou conhecimento prévio das grafias foi muito marcante na população estudada. Este aspecto pode ser inferido a partir da grande diferença observada entre as médias nas tarefas que envolviam o uso das normas ou princípios ortográficos investigados (médias nas tarefas de ditado de palavras e pseudopalavras) e as médias nas tarefas que avaliavam a explicitação dessas mesmas normas e princípios (médias nas tarefas de JG e AP). Ao que parece, estas estratégias são um reflexo da forma como a ortografia tem sido tratada na escola: 
o ensino da gramática, sobretudo dos aspectos relacionados aos processos de formação de palavras do português, são abordados de forma desvinculada das questões ortográficas e essas, por sua vez, são tratadas como "regras" a serem memorizadas pelos estudantes. Tais resultados chamam a atenção para a necessidade de realização de novos estudos, sobretudo de estudos com caráter de intervenção, para que novas abordagens de ensino sejam propostas para o ensino da ortografia do português brasileiro.

O período de escolarização investigado revelou a existência de um salto qualitativo na compreensão e utilização dos aspectos morfossintáticos entre os períodos finais dos ensinos fundamental e médio. Esse salto foi observado diante das diferenças das médias de desempenhos dos estudantes do ensino médio e do ensino superior, quando comparadas às médias dos estudantes do ensino fundamental, que apresentaram desempenho significativamente inferior, nas quatro tarefas avaliadas.

Por outro lado, é importante destacar o baixo desempenho de todos os estudantes, em todos os níveis de escolarização, nas tarefas empregadas. Este aspecto sugere que as dificuldades ortográficas persistem até o final da graduação universitária, o que mostra que a escolarização formal não está assegurando a compreensão e utilização das pistas morfossintáticas na ortografia. Considerando que os estudantes universitários estão no ápice da pirâmide educacional, este resultado chama a atenção para uma possível falha no nosso sistema educacional.

Outro aspecto que merece ser considerado é que há um conhecimento, do senso comum, que estudantes universitários expostos a uma maior carga de leitura e escrita, teriam suas habilidades linguísticas mais desenvolvidas. Os resultados do presente estudam sugerem que isso não ocorre, pelo menos no que se refere à apropriação ortográfica, visto que não se observou o efeito da área do curso de graduação, exatas e humanas, sobre o desempenho ortográfico. Tais resultados, tomados em conjunto com os demais achados do presente estudo, destacam a importância de maior investimento no ensino da ortografia nos anos destinados à Educação Básica.

Dessa forma, as habilidades reflexivas precisam e devem ser trabalhadas desde os primeiros contatos com a língua escrita (educação infantil e período de alfabetização) até o final do ensino médio, período em que todos têm acesso ao estudo formal da língua portuguesa.

\section{Referências}

Carraher, T. N. (1985). Explorações sobre o desenvolvimento da competência em ortografia em português. Psicologia: Teoria e Pesquisa, 13, 269-285.

Cavalcante, T. C. F. (2000). Acessando o conhecimento de regras ortográficas em crianças: um estudo comparativo de diferentes metodologias. (Dissertação de Mestrado). Universidade Federal de Pernambuco.

Chan, L., \& Nunes, T. (1998). Children's understanding of the formal and functional characteristics of written chinese. Applied Psycholinguistics, 19, 115-131.

Faraco, C. A. (1992). Escrita e alfabetização. São Paulo: Contexto.

Guimarães, G. L. (1994). A importância do significado na aquisição da escrita ortográfica. (Dissertação de Mestrado). Universidade Federal de Pernambuco.

Kehdi, V. (2001). Morfemas do português. Série Princípios. São Paulo: Ática.

Levin, I., Ravid, D., \& Rapaport, S. (2001). Mophology and spelling among hebreu-speaking children: form kindergart to first grade. Journal of Chid Language, 28, 741-772.

Meireles, E., \& Correa, J. (2005) Regras contextuais e morfossintáticas na aquisição da ortografia da língua portuguesa por crianças. Psicologia: Teoria e Pesquisa, 21, 77-84.

Melo, K. L. R. (2002). Compreendendo as relações entre consciência gramatical e habilidades de leitura e escrita: um estudo de intervenção. (Tese de Doutorado). Universidade Federal de Pernambuco.

Morais, A. G. (1995). Representaciones infantiles sobre la ortografia del portugués. (Tese de Doutorado). Universidade de Barcelona.

Morais, A. G. (1996). Escrever como deve ser. In A. Teberosky \& L. Tolchinsky (Orgs.), Além da Alfabetização (pp. 61-83). São Paulo: Ática.

Mota, M. (2007). Complexidade fonológica e reconhecimento da relação morfológica entre as palavras: um estudo exploratório. Psic, 8(2), 131-138.

Mota, M., Annibal, L., \& Lima, S. (2008). A morfologia derivacional contribui para a leitura e escrita no português? Psicologia, Reflexão e Crítica, 21(2), 311-318.

Nunes, T., Bryant, P., \& Bindman, M. (1995). E quem se preocupa com a ortografia? In C. Cardoso-Martins (Org.), Consciência Fonológica \& Alfabetização (pp. 129-158). Petrópolis: Vozes.

Queiroga, B. A. M., Lins, M. B., \& Pereira, M. A. L. V. (2006). Conhecimento morfossintático e ortografia em crianças do ensino fundamental. Psicologia: Teoria e Pesquisa, 22(1), 95-100.

Rego, L. L. B., \& Buarque, L. L. (1997). Consciência sintática, consciência fonológica e a aquisição de regras ortográficas. Psicologia, Reflexão e Critica, 10, 199-217.

Vasconcelos, F. C. (1999) A aquisição das representações do fonema /s/ na ortografia do português. (Dissertação de Mestrado). Universidade Federal de Pernambuco.

Bianca Arruda Manchester Queiroga, doutora em Psicologia Cognitiva pela Universidade Federal de Pernambuco, é professora Adjunta da Universidade Federal de Pernambuco (UFPE). Endereço para correspondência: Praça Professor Fleming, 50, 1101, Jaqueira. CEP 52050-180. Recife- PE. E-mail: queiroga. bianca@gmail.com

Lúcia Maria Lins, doutora em Psicologia do Desenvolvimento pela University of Oxford, Inglaterra, é professora do Programa de Pós-graduação em Psicologia Cognitiva da Universidade Federal de Pernambuco (UFPE) (aposentada).E-mail: lucialins@globo.com.br

Antônio Roazzi, doutor em Psicologia do Desenvolvimento pela University of Oxford, Inglaterra, é professor Titular da Universidade Federal de Pernambuco (UFPE). E-mail: roazzi@gmail.com

Rafaella Asfora, doutora em Psicologia Cognitiva pela Universidade Federal de Pernambuco, é professora Adjunta da Universidade Federal de Pernambuco (UFPE). E-mail: rafaellaasfora@gmail.com 